\title{
Body Image of Pakistani Consumers
}

\author{
Tariq Jalees* $\quad$ Ernest $\mathrm{C}$ de Run $^{\dagger}$
}

\begin{abstract}
This paper examines how media exposure, self esteem, and religiosity influence body image of Pakistan consumers. The underpinning of this study is based on Social Comparison Theory with two additional variables (religiosity and self esteem) for understanding understand consumer attitude towards body image. A self administered questionnaire was used. 193 persons responded at mall intercepts. The Conceptual framework was empirically tested through SEM. A positive relationship between exposure to media and body image was found while negative influence was found between self esteem and body image. No relationship was found between religiosity and body image. The results showed mixed outcomes as compared to past studies. The scope of this study is limited to one city only and hence the finding could not be generalized. Future researcher may use a larger sample drawn throughout Pakistan, and by examining whether body image perception varies ethnically, age and gender. Media exposure is affecting the traditional norms and values of Pakistan culture and body image. The obsessions of the media and thin body image have to be controlled and this requires policy changes. Corporate sector might take initiative by not selecting ultra thin models. They might also sponsors public service messages showing ill effects of being ultra thin, and showing that the ultra thin models are not real but is results of artworks and camera angles. Social Comparison Theory with two addition variable religiosity and self esteem has been successfully extended/empirically tested in the domain of Pakistan culture.
\end{abstract}

Keywords: Social Comparison Theory, Media Exposure, Self Esteem Religiosity and Body Image.

\section{Introduction}

A limited numbers of TV channels and magazines were available in Pakistan up to the end of 1980s. In the next few years the growth of media was exponential. As a consequence, now hundreds of foreign and local televisions channels and magazines are available for the local population (Hassan, 2011; "Media Pakistan," 2009). Media exposure has not only revolutionized the culture but has also affected the local population's perception of body image, dressing habits, styles of living and purchasing behavior (Kamran, 2008). Despite its significance insufficient literature on exposure to media and body is available on consumers of Pakistan, India and Sri Lanka is not sufficiently available (Kapadia, 2009). Thus, it arise a need to understand body image

\footnotetext{
*Associate Professor and Head of Marketing,College of Management Sciences, Karachi Institute of Economic and Technology, Creek, Karachi 75190, Pakistan.

${ }^{\dagger}$ Professor and Dean of Graduate Studies Faculty of Economics and Business, University Malaysia Sarawak, Sarawak, Malaysia.
} 
of Pakistani consumers from a theoretical and quantitative purpose.

In order to fill the above gap a conceptual framework has been developed by incorporating religiosity and self esteem as additional variables in the Social Comparison Theory as these have been identified as important variables in the context of Pakistan. Thus this conceptual framework will help in understanding consumer's attitude on body image in a non-Western country namely Pakistan.

\section{Literature Review}

In early nineties body image concerned ( eating disturbance) was not an issue in India (Khandelwal, Sharan, \& Saxena, 1995). In a comparative study between Caucasian and Asians girls it was found that on an overall basis the Asian females were found to be more happier and content with their body image as compared to British Caucasians (Wardle, Haase, \& Steptoe, 2005). Interestingly in another study in the United Kingdom it was found that despite the same exposure to media in England the white females had a higher level of body dissatisfaction and calories concern as compared to the Indian and Pakistani living in the same country (Ogden \& Elder, 1998). Contrarily, others found that both Indian and Pakistani females immigrants living in the United Kingdom were highly dissatisfied with their body images and shapes (Mumford \& Choudhry 2000).

Young Chinese, Indian and European females living in Canada are more concerned about their weight. Indians have more positive body image in comparison to the Chinese, and negative body image as compared to European students (Kennedy , Templeton, Gandhi, \& Gorzalka, 2004). University students in Delhi are of the opinion that there is a high correlation between negative body image and maladjustment. However, they also feel that self esteem acts as a moderator between negative body image and maladjustment (Kapadia, 2009). In a comparative study on Indian and Caucasian students it was found that both the groups feel that for improving the body image necessary remedies are dieting, self induced vomiting, use of laxative and water tablets (Button, Reveley, \& Palmer, 1998). In another cross culture study on Indian, Tibetan, France and American students no correlation was found between socio economics status, media and body image(Rubin, Gluck, Knoll, Lorence, \& Geliebter, 2008).

A comparative study found that Australian females have significantly lower body self esteem, and greater body image dissatisfaction than the Pakistani females belonging to Urdu medium and English medium schools (Mahmud \& Crittenden, 2007) It may be pointed out that students in Urdu medium schools generally belong to lower status and English medium school to upper status. The above perception about body image could be attributed to the difference in socio-culture and religious upbringing of Australian and Pakistani respondents (Dolan, 1991; Nasser, 1988). Both Australian and Pakistani female were also of the opinion that their ideal body size is smaller than their actual body sizes (Mahmud \& Crittenden, 2007).

Media explosion in Pakistan has adversely affected media consumption trend of the local population. On an average they spent three to four hours on media due to which the cultural norms and values are being distorted (Zia, 2007). Moreover, the 